\title{
VICISITUDES DEL CASTILLO SANTIAGUISTA DE NEGRA, EN EL REINO DE MURCIA, BAJO LA CORONA DE ARAGÓN (1296-1304)
}

\author{
JUAN MANUEl DEL ESTAL ${ }^{1}$ \\ Universidad de Alicante
}

El feliz hallazgo de un pergamino inédito de Jaime II de Aragón ${ }^{2}$, referente a la entrega del castillo y villa de Negra por dicho monarca en el reino de Murcia, al caballero santiaguista de Uclés, don Juan López, comendador primero de Socovos (1300, Albacete) y luego de Ricote, (1303,Murcia), nos sugirió el estudio de los avatares político-históricos del lugar referido, durante la pertencecia de aquel reino a la soberanía de Aragón (1296-1304).

Como ya es sabido el reino castellano de Murcía se 'mantuvo incorporado por Jaime II a la corona de Aragón, desde la primavera del

\footnotetext{
'La prolongada convivencia con la activa e infatigable investigadora Regina Sáinz de la Maza Lasoli, durante muchos veranos y reiterados períodos de vacación académica docente, en el ACA, dedicados a una mancomún investigación de los fondos de Jaime II de Aragón, allí existentes, propició el nacimiento de una estrecha relación de verdadera amistad entre ambos, alimentada de palabra y por escrito con el intercambio frecuente de diversos puntos de vista e interpretación documental al respecto, en lo tocante sobre todo al reino de Murcia y muy en particular a las encomiendas de la Orden de Santiago en el mismo. Circunstancia que no me permitía, en modo alguno, quedarme al margen del presente homenaje literario, con esta modesta aportación al tema favorito de su investigación sobresaliente, la Orden de Santiago en la Corona de Aragón y, dentro de ésta, el castillo y villa de Negra, ubicados en una de las más destacadas encomiendas santiaguistas (la de Ricote), en el reino de Murcia.

ACA, C, pergaminos de Jaime II, carp. 167, n 1883, Lérida, 19 mayo 1303. Texto reproducido integramente al final.
}

"Anuario de Estudios Medievales". 28 (1998) 
1296 al estío del $1304^{3}$, resolviéndose los últimos flecos territoriales polémicos de la Sentencia Arbitral de Torrellas (8.VIII.1304) en el Acuerdo de Elche, el 19 de mayo del $1305^{4}$.

En este reino de Murcia, escribía Regina Sáinz de la Maza ${ }^{5}$, "es un hecho conocido, que el señorío de la Orden de Santiago, después del de don Juan Manuel, constituía uno de los poderes más importantes que Jaime II debía atraer a su causa, si quería que la ocupación del mismo fuese un éxito". Ello explica el interés desplegado por este monarca en ganar particularmente a su obediencia soberana las encomiendas santiaguistas murcianas de Aledo, Cieza y Ricote, dependientes a su vez de la encomienda mayor aragonesa de Montalbán. Cometido que explica con difusión y gran autoridad y satisfacción del lector Regina Sáinz de la Maza en la publicación ya citada ${ }^{6}$.

$\mathrm{Y}$ en efecto, antes de haber trascurrido dos meses de la conquista del castillo y villa de Alicante (22.4.1296), prestaron ya homenaje a Jaime II y juraron a su vez acatamiento y obediencia vasallática, el once de junio del mismo año, los comendadores de Ricote, Cieza y Aledo, poniendo a su servicio las respectivas encomiendas con todos los lugares, villas y castillos que poseían en el reino de Murcia, entre los que se contaban el castillo de Negra y el de Peña de Ojós, dependientes a la sazón de Ricote, cuyo comendador era entonces Fernando Pérez ${ }^{7}$.

La contienda armada aragonesa con Castilla por la ocupación del reino de Murcia obligó a Jaime II en los años sucesivos a reforzar y aumentar los pertrechos militares de los castillos santiaguistas murcianos en

\footnotetext{
${ }^{3} J u a n$ Manuel DEL ESTAL. Conquista y anexión del reino de Murcia por Jaime II a la corona de Aragón (1296-1304), Alicante, 1982. pp. 181-285; IDEM, El reino de Murcia bajo Aragón (1296-1305). Corpus documental, I/1, Alicante, 1985; I/2, Alicante, 1990; I/3, Texto e Índices Onomástico. Toponímico y Analítico de toda la obra. Alicante, en prensa, con la amplia bibliografía pertinente.

${ }^{4}$ IDEM, Conquista y anexión, Partición del reino de Murcia, pp. 273-281.

${ }^{5}$ Los santiaguistas del reino de Murcia durante la ocupación aragonesa (1296-1304), "Congreso Internacional Jaime II, 700 años después", Actas, "Anales de la Universidad de Alicante", 11. Historia Medieval, 1996-1997, p. 273.

'Ibidem, pp. 273-299, con Apéndice documental. Este sólido trabajo de investigación es un excelente complemento a su magnífico libro publicado años atrás, La Orden de Santiago en la corona de Aragón. La Encomienda de Montalbán (1210-1327), Zaragoza, 1980, Encomiendas de Murcia durante la dominación aragonesa, pp. 170-177, con un amplísimo Apéndice documental de 236 piezas, en su mayor parte inéditas.

${ }^{7}$ Regina SÁINZ DE LA MAZA, La Orden de Santiago, pp. 170-177; IDEM, Los santiaguistas, pp. 275-276 y 295 .
} 
miras a una defensa más segura y eficaz, al igual que hiciera en las restantes fortalezas de dicho reino ${ }^{8}$. Y así lo hacía saber al maestre don Juan Osores, en marzo del $1298^{9}$, rogándole que autorizase al comendador de Montalbán, García López, la contribución pecuniaria solicitada para la defensa y custodia de los castillos en las encomiendas de Aledo y Ricote y otros lugares santiaguistas ${ }^{10}$, ante el creciente peligro de un ataque castellano.

Sin embargo las buenas relaciones de un principio entre los santiaguistas murcianos y el monarca fueron deteriorándose gradualmente, a partir sobretodo de la creciente presión militar aragonesa, ejercida de modo especial a través de un asedio prolongado del castillo de Lorca, noviembrediciembre del 1300, encaminada a arrancar a sus defensores la capitulación final" ${ }^{11}$. Capitulación que se pactó felizmente el 18 de diciembre de este año ${ }^{12}$, y se llevó a ejecución diez días después ${ }^{13}$, produciéndose la entrega efectiva del alcázar y torres del mismo, Alfonsina, Espolón y Guillén Pérez de Pina, acto que recompensaba Jaime II, al esotro día, 29, prometiendo confirmar a los moradores de Lorca todos los fueros castellanos precedentes, costumbres locales y franquicias ${ }^{14}$.

Pero las deslealtades y traiciones sucesivas de los comendadores santiaguistas murcianos de Aledo, Cieza y Ricote a la causa de Aragón, y en modo muy particular del comendador de Ricote, Fernando Pérez, que "acuylle e recibe nuestros enemigos en los ditos castiellos de la Orden e con complió esto fizo nos perder el castiello de Mula"15, obligaron al monarca

${ }^{8}$ J.M. Del ESTal, El reino de Murcia bajo Aragón, vols. I/1, I/2 y I/3, passim.

".Maestro, ya sabedes de como los castiellos de Ricot et de Alaedo et de otros lugares... son sitiados en el regno de Murcia, los quales por raçón de la guerra, que y es entre nos et Castiella han mester ayuda et socorsso pora la guarda et al retenimiento dellos”, Regina SÁINZ DE La MAZA, La Orden de Santiago, doc. 126, pp. 324-325.

10IDEM, La Orden de Santiago, docs. 125, 127 y 128, pp. 324-326.

"J.M. DEL EsTAL, El reino de Murcia bajo Aragón. Corpus documental , I/2, Alicante, 1990, doc. 134, p. 131; IDEM, Nuevos datos sobre la capitulación y conquista aragonesa de Lorca, "Homenaje al Profesor Juan Torres Fontes", I, Murcia, 1987, pp. 431-440 y doc. 4, pp. 448-449: SÁINZ DE LA MAZA. Los santiaguistas del reino de Murcia, pp. 282-284.

12J.M. DEL EsTAL, El reino de Murcia, I/2, doc. 130, pp. 123-128; IDEM, Nuevos datos, doc. 2, pp. 442-447.

${ }^{13}$ IDEM, El reino de Murcia, I/2, doc. 143, p. 141; IDEM, Nuevos datos, doc. 13, p. 457.

${ }^{14}$ Ibidem, doc. 145 (Lorca, 29.12.1300), pp. 143-144; Nuevos datos, doc. 15, pp. 459-460; Jaime II confirmó en efecto a Lorca todos sus fueros con un privilegio plomado poco después (Murcia, 21.1.1301), ibid., doc. 158, pp. 156-157; Nuevos datos, doc. 19. p. 464.

${ }^{15}$ IDEM, El reino de Murcia, I/2, doc. 134, p. 131: Nuevos datos, doc. 4, pp. 448-449. 
aragonés a denunciar el suceso duramente ante el propio maestre, don Juan Osores, urgiéndole de inmediato la sustitución de este comendador por "algun buen freyre" al "quel fagades comendador de Montalban", e incluso que "al dito Ferran Perez lo fagades eixir de todo el regno (de Murcia)", obligándolo a salir del mismo, ya que le resultaba de todo punto insoportable su manifiesta infidelidad y traición.

En la propia fecha del pacto de la capitulación de Lorca (18.12.1300), al par que Jaime II notificaba al maestre Osores la necesidad de sustituir al comendador de Ricote, Fernando Pérez, por otro "freyre" más leal a la causa de Aragón (quien a su juicio pudiera ser muy bien el comendador de Socovos (Albacete), Juan López, por ser "homne leal e de qui nos e vos podemos fiar" ${ }^{17}$, a quien debería encomendar el gobierno de todos "los lugares que avedes en el Regno nuestro de Murcia e quel asomededes la comendería de Montalban" ${ }^{18}$, al objeto de ejercer mejor la rectoría de todas las encomiendas santiaguistas del reino de Murcia en su condición de comendador mayor de las mismas ${ }^{19}$ ), urgía a su vez al maestre santiaguista, en el plazo de 30 días (18.12.1300-18.1.1301) la entrega de las encomiendas de Aledo, Cieza y Ricote, para mayor seguridad de su causa, mientras perdurase la contienda castellano-aragonesa, comprometiéndose a su devolución inmediata, apenas aquélla hubiese concluido ${ }^{20}$. Ante una eventual respuesta negativa del maestre Osores, el monarca procedería a someter por la fuerza a su obediencia y jurisdicción soberana los referidos enclaves santiaguistas del reino de Murcia ${ }^{21}$.

Jaime II recibió en efecto, dentro del plazo establecido, la guarda y comanda de "todo lo que la Orden de Sant Yago ha en el regno nuestro de

\footnotetext{
${ }^{16}$ Del Estal, Nuevos datos, doc. 4 (Lorca, 18.12.1300) pp. 448-449; R. SÁinz DE LA MAZA. Los santiaguistas, pp. 281-285.

${ }^{17}$ Del Estal, El reino de Murcia. I/2, doc. 135 (Lorca, 18.12.1300), p. 132; IDEM, Nuevos datos, doc. 5, p. 449

${ }^{18}$ Ibidem.

${ }^{19} R$. SÁINZ dE LA MAZA, Los scuntiaguistas, pp. 283-284.

${ }^{20} \mathrm{~J}$.M. Del Estal, El reino de Murcia, I/2, doc. 133 (Lorca, 19.12.1300), p. 130; doc. 136, pp. 133-134: Memorial de los puntos concretos que habría de exponer al maestre Osores el comendador de Socovos, Juan López, en nombre del monarca de Aragón; IDEM, Nuevos datos, docs. 4, 5 y 6, pp. 448-451: R. SÁINZ DE LA MAZA, ibidem.

${ }^{21}$ J.M. DEL ESTAL, El reino de Murcia, I/2, doc. 136 (Lorca, 18-28.12.1300), p. 134: "si el dito Maestro non avia feito fer esto dentro XXX dias, que las cartas del dito rey fueron feytas sobre este feyto, las quales llecva Johan Lopeç, quel dito senyor rey avrá a enantar contra los castiellos e lugares de suso dichos"; IDEM, Nuevos datos, doc. 6, pp. 450-451.
} 
Murcia"22, a tenor de la misiva que le hizo llegar el comendador de la vall de Ricot, Fernando Pérez, de la mano de su escribano, Pedro Ledón. A partir de esta fecha, últimos días del 1300, el monarca de Aragón ostentaba de facto el gobierno de las consabidas encomiendas santiaguistas murcianas, reservando tan solo su correspondiente administración financiera a los comendadores respectivos, contra el parecer y determinación del maestre, don Juan Osores, quien "no se avino a perder el gobierno de los castillos de Murcia, dejando al frente de los mismos a meros administradores, puesto que, aparte de la sustitución en Ricote (de su comendador Fernando Pérez por el aragonés Juan Alvarez) no se produjo en Cieza y Aledo relevo de sus comendadores" 23 .

La reacción hostil del citado maestre no se hizo esperar, estimulado además por la apropiación del castillo y villa de Negra por el rey aragonés, en marzo del 1301, y la concesión real subsiguiente en propiedad al procurador del reino de Murcia, Bernat de Sarriá, en pago a sus buenos servicios en la causa de Aragón ${ }^{24}$. Don Juan Osores, no pudiendo soportar el desmembramiento del patrimonio santiaguista en el reino de Murcia, decidió defenderlo con las armas, enfrentándose en persona con "huestes compuestas de 500 caballeros y 4.000 peones" 25 a los hombres del citado procurador en tierras de Ricote y Cieza, a finales de abril de aquel mismo $a_{n}{ }^{26}$. Al día siguiente de la incursión el concejo de Murcia y el lugarteniente de dicho procurador, Juan de Besora, lo notificaban preocupados al monarca, describiendo con vivo realismo tan lamentable suceso ${ }^{27}$. Tres días tan solo después escribía indignado Jaime II al maestre Osores para reprocharle con duras palabras lo ocurrido y amenazarle seguidamente con la toma de represalias contra "todo aquello que la vuestra Orden ha en la

\footnotetext{
22Ibidem, doc. 144, pp. 142-143 (Lorca, 28.12.1300); Del EsTAL, Nuevos datos, doc. 14 , p. 458: "...nos avemos reçibido todo lo que la Orden de Sant Yago ha en el Regno nuestro de Murcia en nuestra guarda et en nuestra comanda".

${ }^{23}$ R. SÁINZ DE LA MAZA, Los santiaguistas, pp. 283-285

${ }^{24}$ Entregado de lleno a "hacer volver a los santiaguistas rebeldes de Murcia al servicio de Jaime II", R. SÁlNZ DE LA MAZA, Los santiaguistas. p. 286. Por todo ello se hizo merecedor de una recompensa real, "La concesión que el monarca le hizo de la villa santiaguista de Negra", ibidem.

${ }^{25}$ ACA, CRD, Jaime II, caj. 10, n” 1354. R. SÁINZ DE LA MAZA, Ibidem , p. 286.

${ }^{26}$ Ibidem.

${ }^{27}$ ACA, CRD, Jaime II, caj. 10, n" 1354 (Murcia, 23.4.1301). R. SÁINZ DE LA MAZA. ibidem, p. 286
} 
nuestra senyoria" ${ }^{28}$, si no impone el cese inmediato de los violentos ataques referidos.

Don Juan Osores asintió a la demanda regia, no sin antes reclamar al monarca la devolución y restitución a la Orden de la villa y castillo de Negra, en cuyo caso favorable y afirmativo, obtendría en efecto el homenaje requerido a los comendadores murcianos, además del servicio leal de todos los castillos y villas santiaguistas de aquel reino ${ }^{29}$.

Por aquellas fechas, mayo-julio del 1301, Bernat de Sarrià conseguía ganarse la adhesión de los focos rebeldes santiaguistas de Aledo y Ricote a la causa de su soberano y el beneplácito del propio maestre Osores, quien por ello quiso recompensarle su buen éxito negociador, con la entrega del castillo de la Peña de Ojós ${ }^{30}$, por mediación del comendador de Ricote, Juan Alvarez, proclive a la causa de Aragón, pasando a ser ya dos en este momento los castillos santiaguistas en poder de hombres extraños a la Orden, el de Negra y el de Peña de Ojós u Oxós. Durante el 1302 prevalecieron mayormente las buenas relaciones de todas las encomiendas de la Orden de Santiago en el reino de Murcia: Aledo, Cieza, Moratalla, Ricote y Socovos con el monarca de Aragón y su procurador, Bernat de Sarrià ${ }^{31}$, artífice principal de las mismas.

Pero en el curso del 1303 se produce un cambio radical de actitud en las encomiendas santiaguistas murcianas, de franca hostilidad creciente contra Aragón, a raiz de los repetidos conatos de recuperación de aquel reino por Castilla, en cuyo empeño contaron con el apoyo manifiesto de los comendadores de Ricote, Juan López, que había sucedido al proaragonés, Juan Alvarez, fallecido en el otoño de aquel mismo $\mathrm{año}^{32}$, y el de Aledo,

\footnotetext{
${ }^{28} \mathrm{ACA}, \mathrm{C}$, reg. 118 , f. $91 \mathrm{v}-92 \mathrm{r}$ (Valencia, 26.4.1301), Juan TORRES FOnTES, "CODOM" II, Documentos del s. XIII, Murcia, 1969, doc. CXLVI, pp. 150-151; R. SÁINZ DE LA MAZA, La Orden de Santiago, doc. 141, p. 334; IDEM. Los santiaguisias, pp. 286-287.

${ }^{29} \mathrm{ACA}, \mathrm{CRD}$, Jaime II, caj. 10, n"1.351 (Uclés, 27.5.1301), J. TORRES FONTES, ibid., doc. CXLVII, pp. 151-152; R. SÁinz de la MAZA, La Orden de Santiago, doc. 142, pp. 334 335; IDEM, Los santiaguistas, p. 287.

${ }^{30}$ R. SÁINZ dE LA MAZA, Los santiaguistas , pp. $287-288$ y doc. 4 (Lleida, 19.7.1301) pp. 296-297, donde Jaime II reitera al maestre su compromiso formal de entregar a la Orden los castillos mencionados, apenas se haya restablecido la paz entre Castilla y Aragón.

${ }^{31}$ Ibidem, pp. 289-290.

${ }^{32} \mathrm{ACA}, \mathrm{C}$, reg. 201, fol. 56 v: "Licet vobis (Bernat de Sarrià) mandaverimus quod castrum de Negra, quod vos pro nobis tenetis (desde marzo del 1301), redderetis pro nobis Iohanni Lupi, comendatori de Ricot, quia tamen dictus Iohannes Lupi decessit..." (Tortosa, 29.10.1303, falleció entre el 3.9 y 29.10.1303), R. SÁINZ DE LA MAZA, La Orden de Santiago, doc. 157,
} 
Centón Ruiz, quienes "daban cobijo en el castillo a almogávares y castellanos, que insidiaban y capturaban a los aragoneses" ${ }^{33}$. Situación que denunció con gran energía ${ }^{34}$ ante el maestre Osores el monarca aragonés.

$\mathrm{Al}$ objeto de remediar tantos desmanes derivantes de la oposición santiaguista, Jaime II se resolvió al fin por complacer al maestre Juan Osores, aunque tan solo parcialmente ${ }^{35}$, restituyendo el castillo de Negra, en posesión entonces todavía del ex-procurador del reino de Murcia, Bernat de Sarria $a^{36}$, a la Orden de Santiago (19.5.1303), en la persona del caballero santiaguista de Uclés, Juan López ${ }^{37}$, excomendador de Socovos y muy pocos meses después (septiembre) de Ricote ${ }^{38}$. Nos permite esta afirmación el que en el acta notarial de la entrega susodicha no se haga mención alguna de su condición de comendador de Ricote, sino que se le denomine simple y llanamente "Cavalero del Orden de Uclés de la cavallería de Sant Yago". Título que en modo alguno se hubiera omitido de hallarse ya por aquella fecha (mayo 1303) al frente de la encomienda de Ricote, como se haría mención de tal cargo en efecto en la carta de Jaime II al exprocurador del reino de Murcia, Bernat de Sarrià, tres largos meses después (septiembre 1303), en la que se le ordenaba la entrega y restitución del Castillo de Negra"fratri Johanni Lupi comendatori de Ricot" ${ }^{39}$, y no a título personal e individual, sino por su condición jerárquica concreta en la Orden de

p. 343.

${ }^{33}$ ACA. C, reg. 129, fol. 107 v (1303 octubre 3), R. SÁINZ DE LA MAZA, Los santiaguistas, pp. 290-291.

${ }^{34}$ ACA, C, reg. 130, fol. 170r (1303 octubre 29), R. Sálnz dE LA MAZA, ibidem.

${ }^{35}$ Denominamos así esta entrega del castillo de Negra, tan solo parcial, y no plena retrocesión del mismo a la Orden de Santiago, porque se hace tan solo a título personal, en función de la persona individual que la recibe. como caballero de la Orden de Uclés y no como depositario del cargo público que ostenta, en servicio de una colectividad, la Orden de Santiago en este caso.

${ }^{36}$ Sustituido por Bernat de Cruylles el 3 de abril del 1303 en el cargo de procurador del reino de Murcia. J.M. DEL ESTAL, El reino de Murcia, I/2, docs. 229, 230, 231 y 232, pp. 215-218, a quien sucedió muy pocos dias después (29 abril 1303). Pedro de Monteagudo, ibidem, doc. 248, p. 221.

${ }^{37}$ ACA, C, perg. de Jaime II, carp. 167, n" 1883, 400x260 mm. (Lérida, 19.5.1303). Original partido por $A B C$. Inédito. Ofrecemos su transcripción completa en el Anexo documental, $n " 1$.

${ }^{38} \mathrm{AHN}$, carp. 293, n" 4 (Cariñena, 3.9.1303), Juan Torres FonTES, "CODOM”, II, doc. CLI, p. 154.

"Ibidem. 
Santiago, como dirigente y rector de la encomienda que presidía en dicho lugar.

Con anterioridad había ordenado de palabra Jaime II más veces a su consejero real, Bernat de Sarrià, la entrega del citado castillo al comendador de Ricote, Juan López, pero sin resultado alguno ${ }^{40}$. Casi dos meses después (finales de octubre), torna una vez más el rey de Aragón a ordenar a Bernat de Sarrià la susodicha restitución y entrega del castillo de $\mathrm{Negra}^{41}$, pero no ya al comendador de Ricote, Juan López, recién fallecido, sino al comendador mayor de Montalbán, fray Artal de Huerta ${ }^{42}$, monje por lo demás de su entera confianza y favorable de lleno a la causa de Aragón, por lo que se prometía obtener del maestre Osores que lo pusiera al frente "de los castiellos de la Orden que son en el regno de Murcia"43. Y así lo notificaba

\footnotetext{
${ }^{40}$ Ibidem (3.9.1303): "Cum jam mandaverimus vobis oretenus, quod traderetis et restitueretis fratri Johanni Lupi comendatori de Ricot Ordinis Militie Sancti Jacobi castrum de Negra, quod pro nobis tenetis, et intellexerimus per eundem comendatorem quod vos nondum restituistis seu tradidistis sibi dictum castrum...et nunc idem comendator intendat ... mittere aliquem ad vos pro recuperando castro jam dicto... Ideo vobis dicimus et mandamus quatenus dictum castrum tradatis et deliberetis dicto comendatori... prout jam vobis oretenus dedimus in mandatis".
}

${ }^{+1}$ ACA. C, reg. 201, fol. 56 v (Tortosa, 29.10.1303), J.M. Del EsTAL, El reino de Murcia. I/2, doc. 277, p. 245: "Dilecto consiliario suo Bernardo de Serriano etc. Licet nos vobis mandaverimus quod castrum de Negra, quod vos pro nobis tenetis, redderetis pro nobis Iohanni Lupi, comendatori de Ricot, quia tamen dictus Iohannes Lupi decessit et propterea ordinaverimus et velimus quod venerabilis et religiosus Artaldus de Orta, comendator Montisalbani, non ut comendator set ut Artaldus de Orta, teneat pro nobis castrum predictum quod vos tenetis. Ideo vobis dicimus et mandamus quatenus statim dictum castrum traddatis et deliberetis dicto Artaldo...".

+2Se lo hacía saber con estas palabras: "... enbiamos rogar al maestro de la Cavalleria de la Orden de Sant Yago que los castiellos de la Orden que son en el Regno de Murcia los acomiende a nuestros natales, seynaladament a vos et vos presentat le la carta. Otrossi vos fazemos saber que nos embiamos mandar al amado conseyllero nuestro Bernardo de Serrian ... que el castiello de Niegra vos rienda por nos, assí como a don Artal Duerta et no assi como a comendador". ACA, C, reg. 130. fol. 173r (Tortosa, 1.11.1303); R. SÁINZ DE LA MAZA, La Orden de Santiago, doc. 157 , p. 343 y doc. 158, pp. 343-344.

${ }^{43}$ ACA. C, reg. 130, fol. 173 r (Tortosa, 1.11.1303), R. SÁINZ DE LA MAZA. ibidem. doc 158 , p. 343-344. Tres días antes (29 octubre 1303) razonaba Jaime II su determinación y escribía en este sentido al propio maestre Osores: "Maestro, fazemos vos saber que los comendadores que tienen agora los castiellos de la Orden vuestra, que son en el Regno nuestro de Murcia, an feyto et fazen cada dia muytas terrerias et daynos et agraviamientos a las nuestras gentes del dito regno et viene end por esto grant destorbo a nos et mal al dito regno. Ond vos rogamos quanto nos más podemos que vos los ditos castiellos acomendedes a freyres natales nuestros. Et especialment tenemos en nos que sería bueno et assi vos en rogamos quel honrado don Artal Duerta, comendador de Montalbán, qui es de vuestra Orden. los toviesse et no enc vendría ningún dayno a nos ni a nuestra tierra. En otra manera cierto vos fazemos, maestro, que nos no sofririamos daqui adelant que por los ditos comendadores qui agora los tienen, nos sea fecho a nos ni a nuestras gentes dayno ni terrería ninguna, ante y avremos en otra manera a proveyr”, ACA, C, reg. 130, fol. 170 r. J.M. DEL ESTAL, El reino de Murcia, I/2, doc. 276, 
expresamente al propio comendador de Montalbán haber ordenado a su consejero Bernat de Sarrià entregarle el castillo de Negra a título personal y no como a comendador ${ }^{4}$, al objeto de que fueran siendo instalados en las encomiendas santiaguistas del reino de Murcia hombres naturales de Aragón, por razón de que ello comportaría una mejor defensa de la corona ${ }^{45}$. Por cuanto dicho castillo continuaba aun sin ser restituido plenamente a la Orden de Santiago ${ }^{46}$, ya que no se devolvía ni entregaba propiamente a la misma, sino a un freyre santiaguista, sí, pero a título estrictamente personal y particular y no por su condición jerárquica de comendador mayor de Montalbán.

Por todo ello el maestre Osores prosiguió insistiendo todavía ante Jaime II en la restitución y entrega a la Orden de los castillos de Negra y Peña de Ojós, entrambos en poder aun de Bernat de Sarriá. Así se lo hacía saber al monarca a través de un monje santiaguista, enviado al efecto, fray Miguel Pérez, el 30 de diciembre del 1303, reiterándole una vez más: "Otrosi, sennyor, como vos otras vegadas nos anyades prometido de render el nuestro lugar de Negra, que senya la vuestra mercé que nos lo querades e mandedes entregar a este nuestro freyle Miguel Péreç, que a vos enviamos con esta nuestra carta" ${ }^{47}$. Petición que no se vería atendida hasta un a_o después, al ser puesta en ejecución finalmente la Sentencia Arbitral de Torrellas (agosto 1304), el 19 de noviembre de aquel año.

Pero antes de pasar a su exposición, queremos detenernos algo más en el análisis y comentario resultante del documento notarial ya referido, origen de la elección de este tema, por el que Jaime II entregó el castillo y villa de Negra (19.5.1303), en posesión hasta aquella fecha desde 1301 del procurador del reino de Murcia, Bernat de Sarrià, al caballero de la Orden

pp. 244-245.

${ }^{H 4} A C A, C$, reg. 130, fol. 173r. (Tortosa, 1.11.1303), R. SÁINZ DE LA MAZA, La Orden de Santiago, doc. 158, pp. 343-344: "Vos fazemos saber que nos embiamos mandar al amado consseyllero nuestro, Bernardo de Serrian por nuestra carta que el castiello de Negra vos rienda por nos, assi como a don Artal Duerta et no assi como a comendador. E tal es nuestro entendimiento de acomendarvos nos el dito castiello de Negra, assí como a don Artal Duerta et non como a comendador"; IDEM. Los samtiaguistas, p. 291, not. 158.

${ }^{45}$ Ibidem, "por nuestra carta embiamos rogar al maestro de la Cavalleria de la Orden de Sant Yago, que los castiellos de la Orden que son en el regno de Murcia los acomiende a nuestros natales, seynaladament a vos et vos presentat le la carta”. Vid. texto de la nota 43.

${ }^{46} \mathrm{R}$. SÁINZ DE LA MAZA, Los santiaguistas, p. 291.

${ }^{17} A C A$, CRD, Jaime II, caj. 15, n"1905, (El Corral, 30.12.1303), R. SÁInz dE LA MAZA, Los santiaguistas, doc. 5, pp. 297-298. 
de Uclés, Juan López, para que lo tenga, guarde y defienda en su nombre, con plena e inquebrantable fidelidad vasallática ${ }^{48}$.

En primer lugar Juan López, freyre santiaguista de Uclés, recibe la investidura del castillo de Negra de manos del propio rey y no de las de su propio jefe religioso, el maestre de la Orden de Santiago, Juan Osores: "Nos don Jayme... comendamos et livramos a vos don Johan Lopiz, cavalero del Orden de Uclés de la Cavalleria de Sant Yago, el castielo de Negra, asetiado en el Regno de Murcia, en esta manera"49. Prueba inequívoca de actuar el monarca como dueño y señor del mismo, al permitirse la elección del vasallo a su arbitrio y decisión estrictamente personal.

El régimen de la investidura es plenamente vasallático y señorial, y no es vitalicio, ni hereditario en modo alguno, antes bien su concesión está supeditada al tiempo que arbitre libremente su señor, el rey, al que siempre deberá servir y obedecer lealmente. con toda fidelidad, en beneficio y provecho exclusivos de su señor,cual debe hacerlo todo buen hidalgo con su propio señor: "Que tengades aquel castielo por nos et el guardedes bien et lealment a proveyto et a fieldat nuestra, tanto quanto nos querremos, assi como fidalgo tiene et deve tener castielo por su seynor" ${ }^{50}$.

En la tenencia del castillo habrá de servir solo al rey, no haciendo entrega del mismo a ninguna persona fuera de su soberano o enviado suyo, lo que si contraviniere, se verá convertido en un hidalgo infiel y traidor a su señor $^{51}$.

Al tratarse de un acta de investidura señorial, advertimos en ella dos elementos integrantes al par que convergentes entre sí, el uno, el señor, en este caso el rey, y en el otro extremo, el vasallo, aquí en el caso presente, el caballero santiaguista de Uclés, Juan López, ambos extremos reflejados diplomaticamente muy bien en una escritura notarial partida por ABC. En la segunda parte de la misma, asume responsablemente el susodicho recipiendario de la investidura del castillo de Negra, las obligaciones que le son propias de un vasallo leal y fiel, por el tiempo que estime conveniente

\footnotetext{
${ }^{48}$ Vid. supra not. 37.

"Vid. el texto integro en el Anexo documental, 1.

solbidem.

${ }^{51}$ Ibidem: "E aquel castielo a ninguna persona no rendades sino a nos o a qui nos querremos et mandaremos. Et si lo tizierdes, lo que dios non quiera, que finquedes por tal qual deve fincar fidalgo, qui contra voluntat de su seynor, retiene castielo que el es comendado o el rende a otro".
} 
su señor, al que obedecerá siempre en servicio suyo exclusivo y que a nadie más que al él entregará y rendirá dicho castillo o al enviado suyo que a él pluguiere. Y si contraviniere en algo o en todo lo dicho, lo que dios no permita, que se vea incurso en la condición vil de un vasallo infiel y traidor a su señor ${ }^{52}$.

Y en confirmación de cuanto acaba de prometer, lo jura por lo más sagrado, tocando a su vez los Santos Evangelios y la cruz del Señor con sus manos, al par que presta al rey, como a su señor natural, el homenaje vasallático obligado de boca y manos, segun la costumbre de España, la que hacía intransferible el castillo por sucesión hereditaria, siendo por ello su tenencia y posesión siempre revocable a voluntad del rey ${ }^{53}$.

Son firmantes de este acta de investidura señorial el propio rey, Jaime II, como señor infeudante, y el caballero santiaguista, Juan López, como vasallo real infeudado, comprometiéndose entrambos por juramento sagrado a guardar fielmente el compromiso suscrito, explicitando por su parte el vasallo su homenaje fiel al monarca ${ }^{54}$.

Y corroboran la verdad del acta notarial en condición de testigos de excepción, tres freyres de la Orden de Uclés: García Latras, Martín Sanchís y Ramón Çatorre, el comendador mayor de Montalbán, don Artal de Huerta, el consejero real y exprocurador del reino de Murcia, Bernat de Sarrià, Bernat de Bonet, vicecanciller de la corona de Aragón, Pedro de Monels y Ramón de Bosuldu, jueces, y los escribanos reales Bernat de Aversó y Bernat Mayos $^{55}$. Cierra por último este acta y escritura notarial el escribano y notario real, Beltrán Desvall ${ }^{56}$.

\footnotetext{
${ }^{52}$ Vid. Anexo documental. Se repite de nuevo el formulario de la primera parte, en la persona del vasallo en la segunda. Entresacamos tan solo lo siguiente: "Et si lo fizier, lo que dios non quiera, que finque por tal qual deve fincar fidalgo, qui contra voluntat de su seynor retiene castielo que el es comendado o el rende a otro".

${ }^{53} \mathrm{Vid}$. Anexo documental. Reproducimos ahora solamente lo que sigue: "En mayor firmeza fago ende a vos aniantdito seynor homenatge de boca et de manos, segund costumbre d'Espayna". Sobre esta modalidad de tenencia de los castillos según costumbre de España, vid. Maria Teresa FERRER I MALLOL, La tinença a costum d'Espanya en els castells de la frontera meridional valenciana (segle XIV), "La frontera terrestre i marítima amb l'Islam" ("Miscel lània de Textos Medievals"), 4 (Barcelona, 1988), pp. 5-102.

${ }^{54} \mathrm{Vid}$. Anexo documental. Transcribimos aquí la confirmación del vasallo: "Seynal de mi Johan Lopiz, qui estas cosas atorgo, firmo et juro et homenatge en fago".

${ }^{55}$ Vid. Anexo documental.

56“Seynal de mi Beltrán Dezval, escrivano del seynor Rey et notario público por toda la tierra et la seynoría suya, qui a las sobreditas cosas fue present et esto escrivió", ACA, C, pergaminos de Jaime II, carp. $167, \mathrm{n}^{\circ} 1883$, vid. Anexo documental $\mathrm{n}^{\circ} 1$.
} 
Ya hemos subrayado reiteradas veces la insistencia persistente ante el monarca de Aragón del maestre santiaguista, don Juan Osores, en verse correspondido con la devolución a la Orden de Santiago por su parte del castillo y villa de Negra, asi como del de Peña de Ojós, enajenados y absorbidos por él a la misma en el reino de Murcia, desde varios años atrás.

A la embajada del freyre santiaguista, Miguel Pérez de Guasillo, del 30 diciembre del 1303, enviado del maestre Osores ante Jaime II, con el espinoso cometido de obtener la restitución del castillo de Negra a la Orden de Santiago en su persona, sin éxito alguno, antes ya expuesta, siguió otra muy poco después (16 marzo 1304) con idéntico propósito e igual fracaso total, al no verse escuchada ni satisfecha la petición del maestre delegada en él, expresada en esta frase bien elocuente por cierto, "que yo por él lo reçiba" ${ }^{\prime 2}$, y todo fue en vano.

Y medio mes más tarde (30 marzo 1304), tornaba Jaime II a posponer una vez más la restitución del castillo de Negra a la Orden de Santiago, supeditando dicha devolución a su próximo viaje a Murcia, momento entonces en el que "faremos, le decía, a aquello que será bien" 58 . Nuevas largas al fin y más dilaciones reales.

Una circunstancia extraña, por si no era ya bastante turbia la situación, vino a añadirse a las poco buenas relaciones de las encomiendas santiaguistas murcianas con el soberano aragonés, al proporcionar Jaime II a la compañía de jinetes del noble marroquí, Alabbás ben Rahu, su estancia y alojamiento en el castillo de Negra y los lugares de Ceutí y Lorquí de dicha Orden (primer tercio del 1304), desde donde caían por sorpresa en su derredor en pos de razzias y botín, ocasionando en sus frecuentes cabalgadas y correrías no pocos males y asaz grave perturbación social ${ }^{59}$.

Transcurridos algunos meses más de este año y promulgado ya el Fallo Arbitral de Torrellas, donde se fijaba, aunque en forma ambigua y poco clara, la frontera meridional de la corona de Aragón, en el reino de Valencia, con el reino castellano de Murcia, deberían proceder seguidamente los soberanos Jaime II de Aragón y Fernando IV de Castilla, antes de la

\footnotetext{
${ }^{57}$ ACA, CRD, Jaime II, caj. 16, nº 2135, R. SÁINZ DE LA MAZA, Los santiaguistas, p. 292, nota 82 :"Unos días antes el freyre santiaguista, Miguel Pérez de Guasillo, pidió a Jaime II le entregase el lugar de Negra", puesto que el maestre quería "que yo por él lo reçiba".

${ }^{58} \mathrm{R}$. SÁINZ DE LA MAZA, ibidem. 87.

${ }^{59}$ ACA, CRD, Jaime II, caj. 92, n” 11.186, R. SÁINZ DE LA MAZA, ibidem, p. 294 y not.
} 
fiesta de San Lucas o San Martín respectivamente (18 octubre y 11 noviembre), a tenor del mutuo acuerdo real firmado en Tarazona ${ }^{60}$, a la consignación efectiva de los lugares asignados a cadauna de las partes, en las personas de don Artal de Huerta por Aragón y de don Juan Osores por Castilla respectivamente.

En ese ínterin volvió de nuevo el maestre de Santiago a urgir a Jaime II por enésima vez la restitución del castillo de Negra a su Orden (10 octubre 1304), toda vez que el rey castellano acababa de encomendarle hacerse cargo en su nombre de la ejecución efectiva de dicha Sentencia Arbitral en el reino de Murcia ${ }^{61}$. El 26 de octubre le contestaba el monarca aragonés manifestándole estar de acuerdo con él en que se lleve a cabo cuanto antes la consignación de los lugares fijados en la susodicha Sentencia a cada parte implicada y hallarse dispuesto él a su vez a entregarle por fin el castillo y villa de Negra a su Orden, supeditando solamente tal operación a su próxima visita al reino de Murcia ${ }^{62}$.

Por fin la villa y castillo de Negra fueron reintegrados por Jaime II a la Orden de Santiago, el 19 de noviembre del año 1304,certificando en labios del propio maestre Juan Osores, Domingo de Fraga, notario público de Murcia, su efectiva recepción, con estas palabras: "nos don Johan Osoreç ... otorgamos et conosçemos en buena verdat que avemos avido et reçebido et por pagado et por entregado nos tenemos de vos Guillem de Pertusa et de Miguel ça Real, porteros del senyor rey d'Aragon, del castiello et de la villa de Negra, que es de la dicha Orden d'Uclés. El qual castiello et villa entregastes a nos en nombre et en voç de la dicha Orden por mandado del

\footnotetext{
${ }^{60}$ ACA,C, pergaminos de Jaime II, carp. 169, $\mathrm{n}^{0} 2067$ (Tarazona, 13.8.1304), J.M. DEL Estal, El reino de Murcia, I/1, doc. 224, pp. 387-389; IDEM, ibidem, I/3, docs. 164 y 165 , en prensa: "Et esto compliremos l'uno al otro d'aqui a la fiesta de Sant Luch primera que viene, si don Alfonso fillo del infant don Fferrando (de la Cerda), no aprovava l'arbitracion dada entre nos dicho rey de Castiella et el dicho don Alfonso por nos dicho rey d'Aragon et el dicho rey de Portogal. Et si lo dicho don Alfonso aprovava la dicha arbitracion, seamos tenido l'uno al otro de nos faser la dicha restitucion d'aqui a la primera fiesta de Sant Martin que viene".

${ }^{6}$ ACA, CRD, Jaime II, caj. 17, n² 2204 (10 octubre 1304), R. SÁINZ DE LA MAZA, Los santiaguistas, p. 294, nota 88.

${ }^{62} \mathrm{ACA}, \mathrm{C}$, reg. 1521 (erroneamente atribuido a Pedro IV de Aragón), fol. 49 r. Inédito. Transcripción completa en el Anexo documental, 2. Extractamos aquí lo siguiente: "A lo que nos enviastes rogar del vuestro logar de Negra, que vos lo feziéssemos entregado, mucho nos plaze et lo avemos por guisado et vos lo aremos entregar luego que vengades".
} 
dicho rey d'Aragón" ${ }^{63}$. Remitimos al lector al texto que se transcribe íntegro en el Anexo documental.

Por último recogemos la carta que el propio maestre don Juan Osores dirigió a Jaime II (Lorca,22.XI.1304) para notificarle ya satisfecho que sus enviados especiales, Bertrán Desvall su escribano y Guillén de Pertusa y Miguel ça Real, porteros suyos, le habían hecho entrega en efecto de los lugares asignados a Castilla en el reino de Murcia, por el susodicho FalloArbitral, al par que le restituyeron también a su Orden de Santiago el castillo de $\mathrm{Negra}^{64}$, tantas veces reclamado en vano.

Expresaba a su vez al monarca su especial gratitud por la esplendidez y buen comportamiento de sus emisarios reales en la ejecución de la referida Sentencia, ya que "nos an afincado mucho de vuestra parte" ${ }^{65}$. Por cuanto se auguraba que todo ello haya de contribuir al cumplimiento cabal y perfecto de los compromisos adquiridos por uno y otro monarca, ofreciendo él por su parte cuanto esté en su mano para el mayor éxito posible de tal empresa: "et creet por çierto senyor, escribía, que en esto faremos nos todo nuestro poderio que las posturas fechas entre vos et ell (Fernando IV) se tengan et se cumplan" ${ }^{66}$, al objeto de que la difícil paz tan laboriosamente alcanzada entre las coronas de Aragón y Castilla se mantenga firme y segura por largo tiempo. Por su parte el maestre se ofrece además a mediar ante Fernando IV para que todos los compromisos firmados se cumplan por ambas partes felizmente.

Y en confirmación de todo lo dicho añade como colofón final: "que nos fablarem con ell et farem en quanto nuestro poderio cumpliere que se ffaga et que se cumpla en todo et por todo... Et senyor, si algo querederes que nos fagamos por vos, mandat nos, que apareiados somos al vuestro serviçio" ${ }^{\circ}$.

\footnotetext{
${ }^{63} \mathrm{ACA}, \mathrm{C}$, pergaminos de Jaime II, carp. 170, $\mathrm{n}^{0} 2105$. Ofrecemos la transcripción en el Anexo documental, $\mathrm{n}^{\mathbf{0}} 3$, por tratarse de un pergamino original desconocido.

${ }^{64} \mathrm{ACA}, \mathrm{C}$, pergaminos de Jaime II, carp. 170, n⿳ 2107 (Lorca, 22 noviembre 1304): "Et nos de los dichos lugares en nombre et en voç del dicho senyor rey de Castiella nos atorgamos por pagado et por entregado, es a saber del alcaçar et de la cibdat de Murcia, del castiello de Montagut, de la villa et del castiello de Molina Seca, d'Alhama et de la villa et del castiello de Lorca con todas fortalessas dende et por nos et por nuestra Orden del castiello de Negra"

${ }^{65}$ Ibidem.

${ }^{66}$ Ibidem. Ofrecemos la transcripción del texto de un pergamino original, que mejora las lecturas ya conocidas, Anexo documental, $n^{\circ} 4$.

${ }^{67}$ Ibidem.
} 
Quedaba así de este modo restaurada al fin la antigua buena amistad existente entre el monarca Jaime II de Aragón y el maestre de la Orden de Santiago, don Juan Osores. 


\section{ANEXO DOCUMENTAL}

1303, mayo 19. Lérida.

Jaime II hace entrega del castillo de Negra en el reino de Murcia al caballero santiaguista de Uclés, don Juan López, a condición de que le sirva y lo defienda según la costumbre de España, frente a todos los enemigos, jurando éste por su parte que lo guardará y defenderá con toda firmeza y fidelidad como corresponde a un buen vasallo suyo.

ACA. C, pergaminos de Jaime II, carp. $167, \mathrm{n}^{\circ} 1883,400 \times 260 \mathrm{~mm}$. Original partido por $A B C$. Inédito.

Nos don Jayme por la gracia de dios rey d'Aragón, de Valencia et de Murcia, conte de Barcelona et seynalero de la eglesia de Roma, almirant et capitaneo general. Comendamos et livramos a vos / don Johan Lopiz, Cavalero del orden d'Uclés de la cavallería de Sant Yago, el Castielo de Negra, assetiado en el Regno de Murcia en esta manera: que tengades aquel Castielo por nos, et el guardedes bien et / lealment a proveyto et a fieldat nuestra, tanto quanto nos querremos, assi como fidalgo tiene et deve tener castielo por su seynor. Et aquel castielo a ninguna persona no rendades, sino a nos o a qui / nos querremos et mandaremos. Et si lo fizierdes, lo que dios non quiera, que finquedes por tal qual deve fincar fidalgo, qui contra voluntad de su seynor, retiene castielo que'l es comendado, o'l rende a otro $/$.

E yo Johan Lopiz desuso dito, entendiendo que tengo el castielo de Negra por vos seynor don Jayme Rey d'Aragón sobredito, prometo aquel castielo de Negra guardar bien et fielmente a proveyto et a / honrra vuestra tanto quanto a vos ploguiere et aquel castielo a vos render irado (sic) et pagado, quandoquiere que de nos ne será requerido o demandado o amonestado personalmientre en qualquiere logar o citado en / aquel castielo sobredito, assi como vassalo es tenido de render a su seynor el castielo que por él tiene e vengo'n vuestro vassallo et aquel a ninguna otra persona no rendre si no a vos o a qui vos querre-/des o mandaredes. Et si lo fizier, lo que dios non quiera, que finque por tal qual deve fincar fidalgo, qui contra voluntat de su seynor retiene castielo que'l es comendado o'l rende a otro. 
Juro por / los santos evvangellos et la cruz del nuestro seynor ante mi posados et tocados todas las sobreditas cosas, a tener firmemente et complir et contra d'aquellas no venir por ninguna manera.

En mayor fir-/meza fago ende a vos aniantdito seynor homenatge de boca et de manos segund custumbre d'Espayna.

Feyto fue esto en Lérida, XIX dias andados del mes de mayo. En el ayno del nuestro seynor de / mil trezientos et tres.

Seynal (signo real) de nos don Jayme por la gracia de dios Rey d'Aragón sobredito, qui estas cosas loamos, atorgamos et firmamos /.

Seynal (signo del vasallo enfeudado) de mi Johan Lopiz sobredito, qui estas cosas atorgo, firmo et juro et homenatge en fago $/$.

Testimonios son desto García Latras, Martín Xanxiz, Ramón Çatorre, freyres de la orden d'Uclés, el noble don Artal d'Uerta, Bernat de Sarrian, conseyllero, Bernat Bonet, vicecancellero, Pedro de / Monels, Ramón de Bosuldu, jutges, Bernat d'Aversó et Bernat Mayos, escrivanos del seynor Rey $/$.

Seynal (signo del escribano y notario real) de mi Beltrán Dezval, escrivano del seynor Rey et notario público por toda la tierra et la seynoría suya, qui a las sobreditas cosas fue present et esto escrivióa

"Respetamos todas las grafías del original, salvo las ues correspondientes a mes.

1304, octubre 26. Valencia.

Carta de Jaime II al maestre de la orden de Santiago, don Juan Osores, donde le notifica que ya queda al corriente de su designación por el rey de Castilla, Fernando IV, para recibir de Aragón la entrega de los lugares asignados al reino de Murcia, en la Sentencia Arbitral de Torrellas, asicomo que él se halla dispuesto también a recibir de sus manos aquéllos asignados a su propia corona, al par que le certifica estar plenamente de acuerdo en devolver a la orden santiaguista el castillo de Negra en dicho reino, por ser de su propiedad.

ACA, C, reg. 1521 (Varia 1" / Petri III pro negotiis Castellae / et Aragonum, de 1312 a $49 \%$. Con rectificación de mano posterior de la palabra Petri III por la de Jacobi ll y de los años 1312 a 49 por los de $13(1) 4$ a 1326), foll. 49) r. Inédito. 
Don Jayme etc. Al muy honrrado et religioso don Johan Osores de la orden de la cavallería de Sant Yago, salut. Com / a aquél que mucho amamos et de quien mucho fiamos et pora quien querríamos mucha honrra et buena ventura. Recibiemos I vuestra carta en la qual nos feziestes saber que avíades enviado al Rey de Castiella vuestras cartas en las quales le pedíades / mercé, que con tal recaudo et en tal manera vos enviasse al Regno de Murcia, que vos podiessedes recibir desembargada- / ment lo que nos aviamos a entregar, et nos otrossi oviéssemos lo que aver devemos segund la Sentencia.

Et vos (borroso) / feziestes esto muy bien et de lo nuestro otrossi que desembargado sea quandoquier que vos veresdes. E como quiere que / viniéssemos en las partidas del Regno de Valencia por razón de los moros et por su gran partida viniemos por esta razón por / tal que aquello que nos devemos fazer entregar se feziesse más desembargadament sin alongamiento.

A lo que nos enviastes / rogar del vuestro logar de Negra, que vos lo feziéssemos entregado, mucho nos plaze et lo avemos por guisado et vos lo are-/mos entregar luego que vengades.

Datum Valentie VII kalendas novembris anno predicto/. (1304).

Bernardus de Aversone mandato regis ${ }^{a}$

"Respetamos todas las grafías del original, salvo las ues correspondientes a wees.

1304, noviembre 19. Murcia.

Acta notarial de la entrega del castillo y villa de Negra por los procuradores de Jaime II de Aragón, Guillén de Pertusa y Miguel ça Real, al maestre santiaguista, don Juan Osores, en nombre de la orden de Uclés.

ACA, C, pergaminos de Jaime II, carp. 170, $\mathrm{n}^{\circ} 2105,290 \times 150 \mathrm{~mm}$. Original.

Sepan quantos esta carta vieren, commo nos don Johan Osoreç por la gracia de dios maestro de la orden de la cavalleria de Santyago, otorgamos et conosçemos en buena verdat que avemos avido / et reçebido et por pagado et por entregado nos tenemos de vos Guillem de Pertusa et de Miguel ça Real, porteros del senyor Rey Daragon, del castiello et de la villa de Negra, que es / de la dicha orden Ducles. El qual castiello et villa entregastes a nos en nombre et en voç de la dicha orden por mandado del dicho Rey Daragon. 
Et desto los dichos porteros demandaron a mi Domingo de Ffraga /, notario publico de Murcia que les ende fisies esta carta publica en testimonio de verdat. Ffecha la carta en Murçia, deçenou dias de novembre, anno domini millesimo tres/centesimo quarto.

Signo (signo del maestre) de nos don Johan Osoreç, maestro sobredicho, qui esto loamos, firmamos e otorgamos /.

Testimonios son desto Bertran de Ribas Altas, comendador de Caravaca. Alfonsso Yannes (Yvannes?), comendador de Ricot. Munyo (Muyero?) Gonçalveç, comendador / de Çeça (Cieza). Johan Nicholay. Pere de Montagut, procurador del Regno de Murçia. Bertran Deçvall, escrivano del senyor Rey Daragon et Guillem Mir./

Senyal (signo notarial) de mi, Domingo de Ffraga, publico notario de Murçia, qui esta carta escrivy e a esto presente fuy, en el ayno, dia e lugar sobredichos e acloy ${ }^{\mathrm{a}}$.

"Respetamos plenamente todas las grafías peculiares del texto.

1304, noviembre 22. Lorca.

Carta del maestre de la Orden de Santiago, don Juan Osores, notificándole haberle sido ya devueltos por sus enviados los lugares asignados al rey de Castilla en el reino de Murcia por la sentencia arbitral de Torrellas, destacando también la devolución por fin del castillo de Negra a la Orden Santiaguista.

ACA, C, pergaminos de Jaime II, carp. 170, $\mathrm{n}^{\circ} 2107$. Original (230) $\left.160 \mathrm{~mm}\right)$.

Al muy alto e bien aventurado senyor don Jayme por la gracia de dios rey Daragon. / Nos don Johan Osoreç por essa misma gracia maestro de la orden de la cavalleria / de Santyago, besando vuestras manos nos comendamos a vuestra gracia, commo de / senyor de quien atendemos mucho bien et mucha merçet.

Senyor, sepades que'l honrado et discreto don Bertran Desvall escrivano, Guillem de Pertusa et / Miguel ça Real vuestros porteros, por mandamiento vuestro me an entregado e puesto / en corporal possession de todos aquellos lugares que vos aviades a delivrar e / a entregar al senyor rey de Castiella segund la arbitraçion e sentençia entre vos / e ell dada con la condiçion e manera que vos enbiastes por los sobredichos escri-/vano et porteros. Et nos de los dichos lugares en nombre et en voç del dicho senyor / rey de Castiella nos atorgamos por pagado e por entregado, 
es a saber del / alcaçar et de la cibdat de Murcia, del castiello de Montagut, de la villa e del cas-/tiello de Molina Seca, Dalhama e de la villa e del castiello de Lorca con todas / fortalesas dende et por nos et por nuestra orden del castiello de Negra.

Et sabet senyor que de la entrega et de todas las otras cosas que'l senyor rey de cas-/tiella a vos a de faser et de complir segund las posturas que son entre vos et ell, que nos / fablarem con ell et farem en quanto nuestro poderio cumpliere que se ffaga et que se cumpla / en todo et por todo. Et desto senyor sabet que ell honrado don Artal Dorta comenda-/dor de Montalban et el dicho don Bertran Desvall nos an afincado mucho de vuestra / parte et creet por çierto senyor que en esto faremos nos todo nuestro poderio que las / posturas fechas entre vos et ell se tengan et se cumplan.

Et senyor si algo quere-/deres que nos fagamos por vos, mandat nos, que apareiados somos al vuestro serviçio. Et / dé vos dios vida et salut.

Data en Lorca, domingo, XXII dias de noviembre, / anno domini millesimo trescentesimo quarto.

\section{RÉSUMÉ}

Dans cette collaboration est exposée l'évolution oscillante que présente le châteaufort et la ville de Negra, dans le cadre de la commanderie de l'ordre de Saint-Jacques de Ricote, dans le royaume de Murcie, sous la souveraineté d'Aragon (1296-1304).

L'origine de ce travail fut l'heureuse trouvaille d'un parchemin inédit de Jaume II d'Aragon (19.V.1303) par lequel le château-fort et la ville de Negra étaient livrés au chevalier de l'ordre de Saint-Jacques de Uclés, Juan López, ancien commandeur de Socovos et ensuite commandeur de Ricote.

La bataille castillane-aragonaise pour la possession du royaume de Murcie, mena Jaime II à assurer le vasselage des commanderies murciennes de l'ordre de Saint-Jacques, face aux attaques castillane-granadins. Pour cela, il n'hésita pas à s'emparer des châteauxforts de Saint-Jacques de Negra et de Ojós (Oxóx) et les remettre en propriété au procureur du royaume de Murcie, Bernat de Sarrià (1301), avec la manifeste opposition de son maître général, don Juan Osores.

Jaime II contrevint encore plus les interêts murciens de Saint-Jacques en offirant le château-fort de Negra (1303 au chevalier déjà nommé, Juan López, en pleine condition de vasselage à son royal seigneur d'Aragon. Les vicissitudes de ce château-fort se prolongeraient encore pendant plus d'un an et demie, jusqu'à sa dévolution finale à l'ordre de Saint-Jacques, en novembre de 1304. 


\section{SUMMARY}

This paper is devoted to study the waveing evolution of the castle and the town of Negra, in the Order's commandery of Ricote, within the kingdom of Murcie and under the sovereignty of Aragon (1296-1304).

This work has its origin in an unedited parchment of Jaime II de Aragon (19.V.1303), in which he handed the castle and the town of Negra over to Juan López, a knight of the Order of Saint-James from Uclés, ex knight commander of Socovos and later knight-commander of Ricote.

The conflict between Castile and Aragon about the possession of the kingdom of Murcia made Jaime II secure for himself the vassalage of the Murcian Order's commandery in front of Castilian-Grenadine attacks. Without delay, he took possession of the Order's castles of Negra and Ojós (Oxóx), and gave them over in property to the procurator of the kingdom of Murcia, Bernat de Sarrià (1301), with the opposition of his general master, don Juan Osores.

Jaime II contravened the Murcian Order's interests stil more, by bestowing Negra's castle on the aforementioned knight, Juan López, in full accordance with the vassalage state to his royal Lord of Aragon. The vicissitudes of this castle would continue on for a space of more than a year and a half, until its final devolution to the Order of Saint-James, in Novembre 1304. 